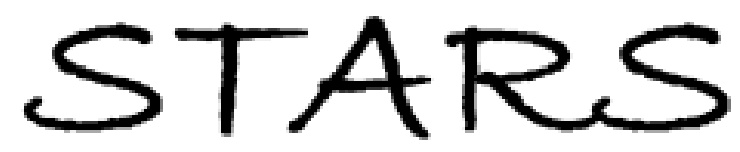

University of Central Florida

STARS

$1-1-2005$

\title{
Optoelectronically automated system for carbon nanotubes synthesis via arc-discharge in solution
}

\author{
Debasis Bera \\ University of Central Florida \\ Erik Brinley \\ University of Central Florida \\ Suresh C. Kuiry \\ University of Central Florida \\ Matthew McCutchen \\ University of Central Florida \\ Sudipta Seal \\ University of Central Florida \\ Find similar works at: https://stars.library.ucf.edu/facultybib2000 \\ University of Central Florida Libraries http://library.ucf.edu \\ See next page for additional authors
}

This Article is brought to you for free and open access by the Faculty Bibliography at STARS. It has been accepted for inclusion in Faculty Bibliography 2000s by an authorized administrator of STARS. For more information, please contactSTARS@ucf.edu.

\section{Recommended Citation}

Bera, Debasis; Brinley, Erik; Kuiry, Suresh C.; McCutchen, Matthew; Seal, Sudipta; Heinrich, Helge; and Kabes, Bradley, "Optoelectronically automated system for carbon nanotubes synthesis via arc-discharge in solution" (2005). Faculty Bibliography 2000s. 4995.

https://stars.library.ucf.edu/facultybib2000/4995

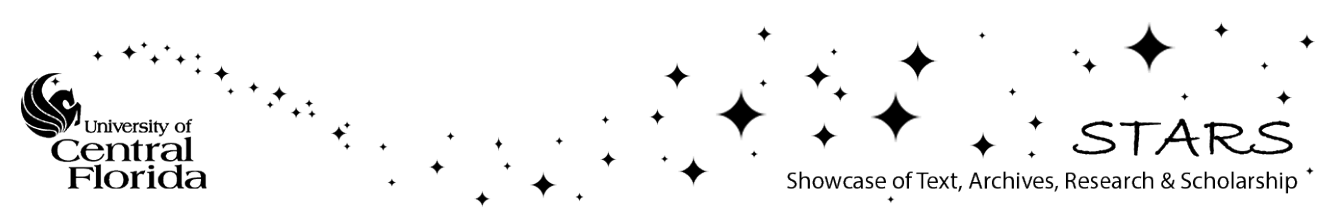




\section{Authors}

Debasis Bera, Erik Brinley, Suresh C. Kuiry, Matthew McCutchen, Sudipta Seal, Helge Heinrich, and Bradley Kabes 


\title{
Optoelectronically automated system for carbon nanotubes synthesis via arc-discharge in solution
}

\author{
Debasis Bera, Erik Brinley, Suresh C. Kuiry, Matthew McCutchen, and Sudipta Seal ${ }^{\text {a) }}$ \\ Surface Engineering and Nanotechnology Facility (SNF), Advanced Materials Processing and Analysis \\ Center (AMPAC), and Mechanical, Materials and Aerospace Engineering (MMAE), University of Central \\ Florida (UCF), 4000 Central Florida Blvd., Eng 1, \#381, Orlando, Florida 32816
}

Helge Heinrich

Advanced Materials Processing and Analysis Center (AMPAC) and Department of Physics, University of Central Florida, 4000 Central Florida Blvd., Eng 1, \#381, Orlando, Florida 32816

Bradley Kabes

NSF REU Site (UCF), Department of Chemical Engineering, University of Minnesota, Duluth, Minnesota 55803

(Received 14 September 2004; accepted 10 December 2004; published online 8 February 2005)

The method of arc discharge in the solution is unique and inexpensive route for synthesis of the carbon nanotubes (CNTs), carbon onions, and other carbon nanostructures. Such a method can be used for in situ synthesis of CNTs decorated with nanoparticles. Herein, we report a simple and inexpensive optoelectronically automated system for arc discharge in solution synthesis of CNTs. The optoelectronic system maintains a constant gap between the two electrodes allowing a continuous synthesis of the carbon nanostructures. The system operates in a feedback loop consisting of an electrode-gap detector and an analog electronic unit, as controller. This computerized feeding system of the anode was used for in situ nanoparticles incorporated CNTs. For example, we have successfully decorated CNTs with ceria, silica, and palladium nanoparticles. Characterizations of nanostructures are performed using high-resolution transmission electron microscopy, scanning transmission electron microscopy, energy dispersive spectroscopy, and scanning electron microscopy. (C) 2005 American Institute of Physics. [DOI: 10.1063/1.1857465]

\section{INTRODUCTION}

Although carbon nanotubes (CNTs) can be synthesized using a variety of techniques, the following three methods are mainly used for commercial and bulk production of carbon nanotubes: arc discharge; chemical vapor deposition; and laser ablation. The last two methods generally rely on the presence of metal catalysts in the form of nanoparticles that are either available during the process of synthesis or planted previously on the templated substrate. Such procedures cause dispersion of catalytic nanoparticles along the CNT specimen. More than 1100 papers and about 100 patents related to synthesis aspects of CNTs have been published to date. ${ }^{1}$ Despite such tremendous research efforts, low-cost, large-scale production of high quality CNTs is yet to be reported, ${ }^{2}$ due to the proprietary nature of all the processes. High cost, complicated instrumentation for synthesis of CNTs, along with maintaining high vacuum conditions, have made the above-mentioned methods inaccessible to the majority of researchers across the world. Recently, arc discharge in the liquid phase has attracted considerable attention due to its simplicity. ${ }^{3-14}$ Without maintaining a vacuum, carbon nanostructures can be synthesized with such technique. The method has not only assisted production of clean CNTs,

\footnotetext{
${ }^{\text {a) }}$ Author to whom correspondence should be addressed; electronic mail: sseal@pegasus.cc.ucf.edu
}

but also the synthesis of in situ decorated CNTs with metallic and ceramic nanoparticles. ${ }^{5,13,14}$ A number of investigations on the arc discharge in the solution (ADS) showed its promising potential for the synthesis of various carbon nanostructures. ${ }^{4-14}$ Although the method is highly efficient for bulk production, a full-fledged instrumentation for such a method is not yet reported. However, automation of arc discharge in vacuum is reported in literature. ${ }^{15}$

In the ADS method, the anode and cathode are brought in contact to strike an arc. They are separated to a distance of about $1 \mathrm{~mm}$ to sustain the arc inside the liquid. The temperature in the region of the arc is greater than $3500{ }^{\circ} \mathrm{C}$. Hence, the plasma region produced by the arc adjacent to the electrodes is enveloped by a liquid-vapor interface. There is a substantial thermal gradient across the plasma region. The temperature at the anode edge is more than $3500{ }^{\circ} \mathrm{C}$, while it is $100{ }^{\circ} \mathrm{C}$ at the solution-vapor interface. The volume of the plasma region depends on the distance between the cathode and the anode. Arcing results in consumption of the anode and the simultaneous deposition of the carbon nanostructures on the cathode. The fraction of carbon deposited on the cathode depends on the volume of the plasma. Thus, the influence of the relative distance between two electrodes during ADS is a very important factor for overall system performance. Second, for the synthesis of CNTs decorated with nanoparticles, a precursor solution is generally used for ADS method, which produces various noxious gases, such as car- 


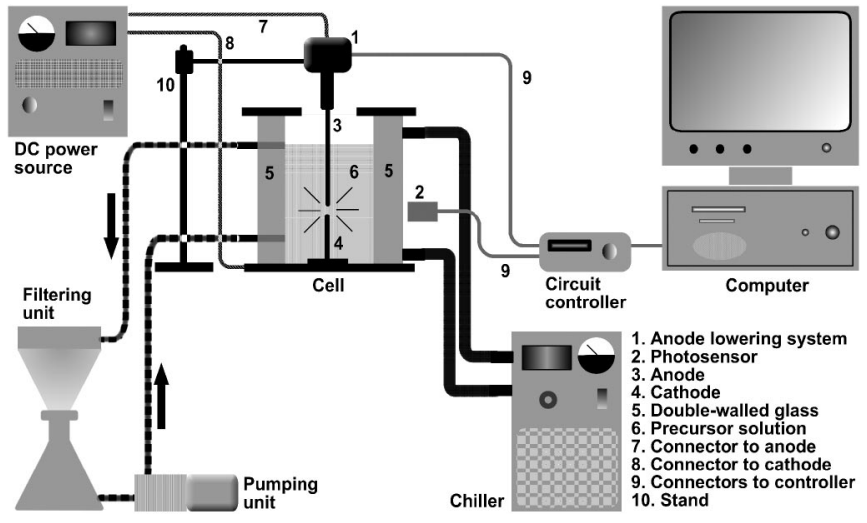

FIG. 1. Schematic diagram of the whole setup for synthesis of carbon nanotubes (CNTs) and nanoparticles decorated CNTs using ADS method.

bon monoxide, carbon dioxide, chlorine, etc., along with water vapor as by-products. ${ }^{13,14}$ Such gases and excessive heat may be harmful to humans when it is operated manually. Automation of the system for the arc discharge in the solution is proposed as a way to perform the experiment without the need of much human interaction and to allow for bulk production of CNTs in a much safer environment.

The aim of the present work is to develop a simple and inexpensive instrumentation for the bulk synthesis of carbon nanostructures and in situ decorated CNTs with industrially important nanoparticles. The present study also focuses on the building up of the set and its optoelectronic automation. Using this setup, CNTs decorated with palladium, ceria, and silica nanoparticles have been successfully synthesized. Synthesized nanostructures are characterized by scanning electron microscopy (SEM), transmission electron microscopy (TEM), scanning transmission electron microscopy (STEM), and energy dispersive spectroscopy (EDS) for their size, morphology, and elemental information.

\section{EXPERIMENT}

\section{A. Setup for arc discharge in solution}

Two main units are necessary for the setup: a unit of basic components for arc discharge and an optoelectronical controlling unit. A schematic diagram showing all parts of the two main components are shown in Fig. 1.

\section{Basic components}

The basic components of the setup for arc discharge in solution are composed of (1) a cell, (2) a direct current (dc) power supply system, (3) a filtering unit, and (4) a chilling loop. The cell is the main part of the whole setup. The electrodes are brought in contact to strike an arc inside the cell. Figure 2 shows a three-dimensional diagram of the cell with a height of $20 \mathrm{~cm}$ that consists of a double walled glass with $2 \mathrm{~cm}$ thickness for a flow of cooling water at $7{ }^{\circ} \mathrm{C}$. The outer and the inner walls are marked "i" and "j" in Fig. 2, respectively. The inner diameter of the cylindrical cell is $10 \mathrm{~cm}$. The cell has two inlets, labeled "d" and "e" in Fig. 2, and two outlets, labeled "c" and "f." One pair of inlet and outlet is connected to the volume between the double walls for the cooling of the cell with a flow of chilled water as shown in

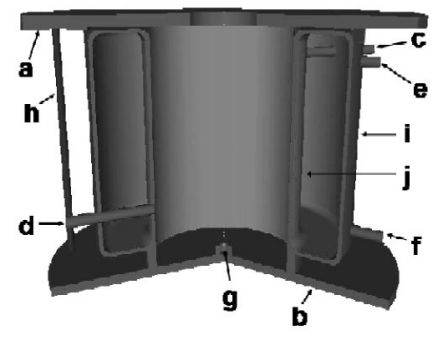

FIG. 2. Three-dimensional view of the cell (not in scale). (a) Upper stainless steel plate, (b) lower stainless steel plate, (c) outlet from inner volume to filtering unit, (d) inlet to inner volume from filtering unit, (e) and (f) pair of inlet and outlet, connected between outer volume and chiller, $(\mathrm{g})$ cathode holder, (h) one of the three metal rods for holding top and bottom stainless steel plate together, they are situated at $120 \mathrm{deg}$ from each other, and (i) and (j) outer and inner walls, respectively.

Fig. 1. The other pair is directly connected to the interior of the cell for filtering out the carbon nanotubes from the cell and filling the cell with filtered solution, as shown in Fig. 1. Two stainless steel plates are placed on the two open ends of the cylindrical cell. These plates are labeled as "a" for the upper stainless steel plate and "b" for the lower stainless steel plate. The bottom stainless steel plate is used to attach the cathode electrode through a holder indicated by "g" in Fig. 2. Three metal connecting rods outside the cell are $120^{\circ}$ apart from each other to hold the two stainless plates together. One such rod has been shown in Fig. 2 as "h." The anode electrode is connected to the anode lowering unit labeled as "l" in Fig. 1. The lowering unit allows the anode to move along its vertical path.

\section{Optoelectronic control unit}

The concept of the optoelectronically optimized automation process is presented in Fig. 3. It was adopted to make the arc-discharge process continuous by feeding the anode electrode vertically toward the cathode. A preselected constant distance can be maintained between the two electrodes using the optoelectronic system to sustain the arc. The system consists of three main components: (a) a photosensor for an optical emission diagnosis, (b) a feedback loop which is composed of analog electronics and a computing unit, and (c) a servounit for $Z$-axis translation of the anode. The servounit, which is shown in Fig. 1 as the anode lowering sys-

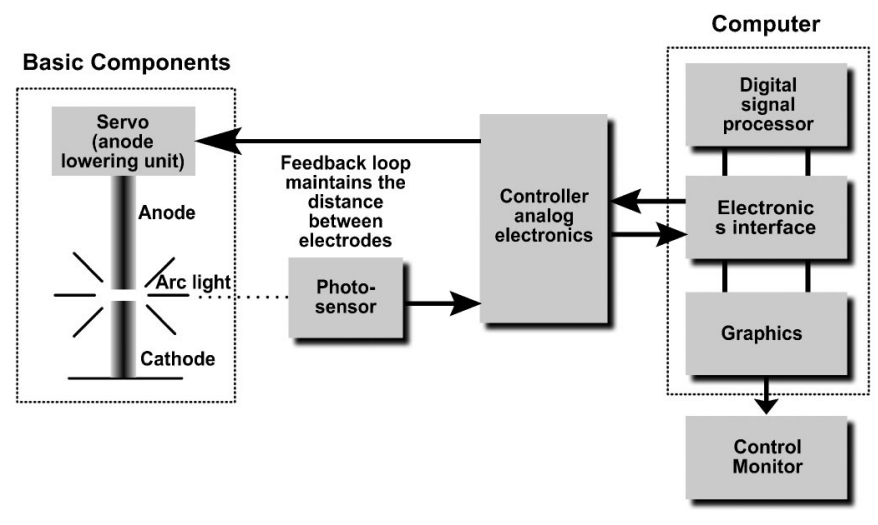

FIG. 3. Block diagram showing the concept and major components of the optoelectronic feedback control of the electrode feeding system that is implemented in the present ADS process. 


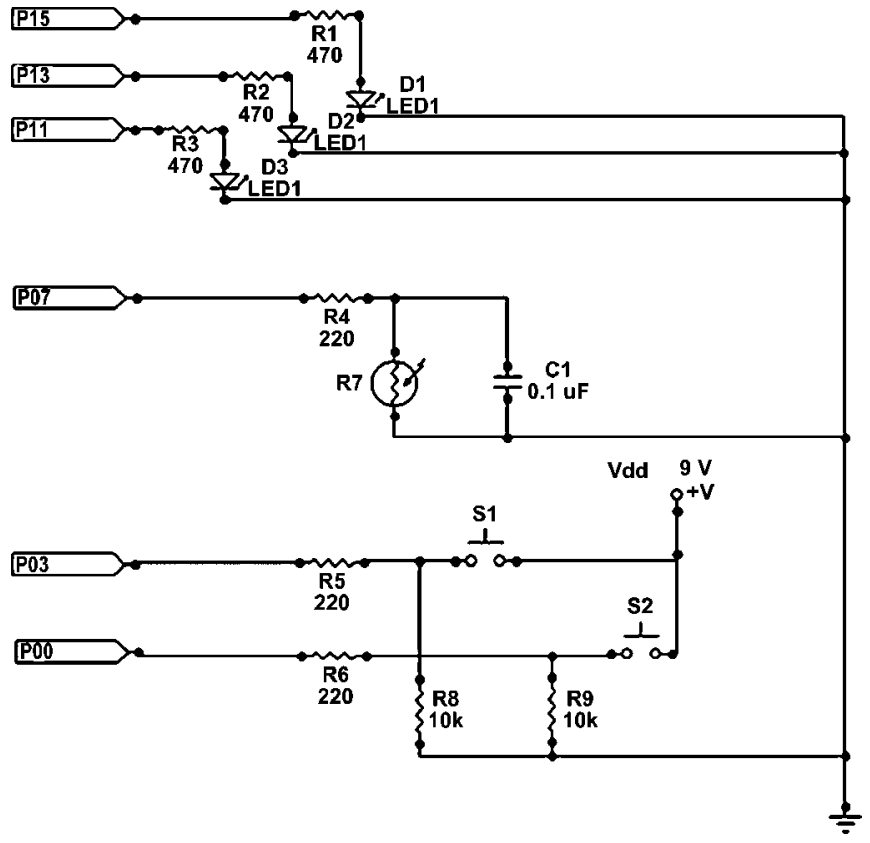

FIG. 4. Integrated circuit of controller analog electronics. $R$ : resistor, $C$ : capacitor, LED: light emitting diode, $S$ : switches, and $P$ : input pins.

tem, is coupled with $X, Y$, and $Z$ translational levers. The servounit is controlled by pulse from analog controller unit. The speed of $Z$ translation depends on the duration of the pulses which are specified by the analog controller unit. Generally, $X$ and $Y$ positions are specified by the user before the arc discharge process begins. Since the $Z$ position is solely based on pulse and pulse duration, very precise movements along the $Z$ axis are easily achievable.

The electronics of the analog controller unit is a kit of the BASIC stamp (Home version). The electronic circuit of the controller is presented in Fig. 4. It is basically a programmable logic device. Such a BASIC stamp kit consists of necessary parts including resistors, light emitting diodes (LEDs), push buttons, and capacitors. The whole unit is powered by a $9 \mathrm{~V}$ battery. The capacitor is in parallel with the photosensor. The pins, which are shown in Fig. 4, are used as signal inputs and outputs.

A program was used to communicate to the integrated circuit of BASIC stamp by means of a computing unit. The language of the program is a derivative of BASIC. A program was written on a WINDOWS-based computer using the BASIC stamp program as an editor. The program was then transferred to the integrated circuit of the analog controller unit from the computer through a COM 1 serial link. The feedback information from the analog controller unit feeds to the computer through the same serial link. The information is immediately directed to the WINDOWS program that interprets the data. Such a program can be used for user input. Throughout this process the digital processor handles the necessary computations to run the system. The graphics can be used to plot the data in real time as well as after the completion of the synthesis process.

\section{B. Logic of automation}

The program consists of few main blocks including initialization and a feedback loop. A flow-chart diagram of the

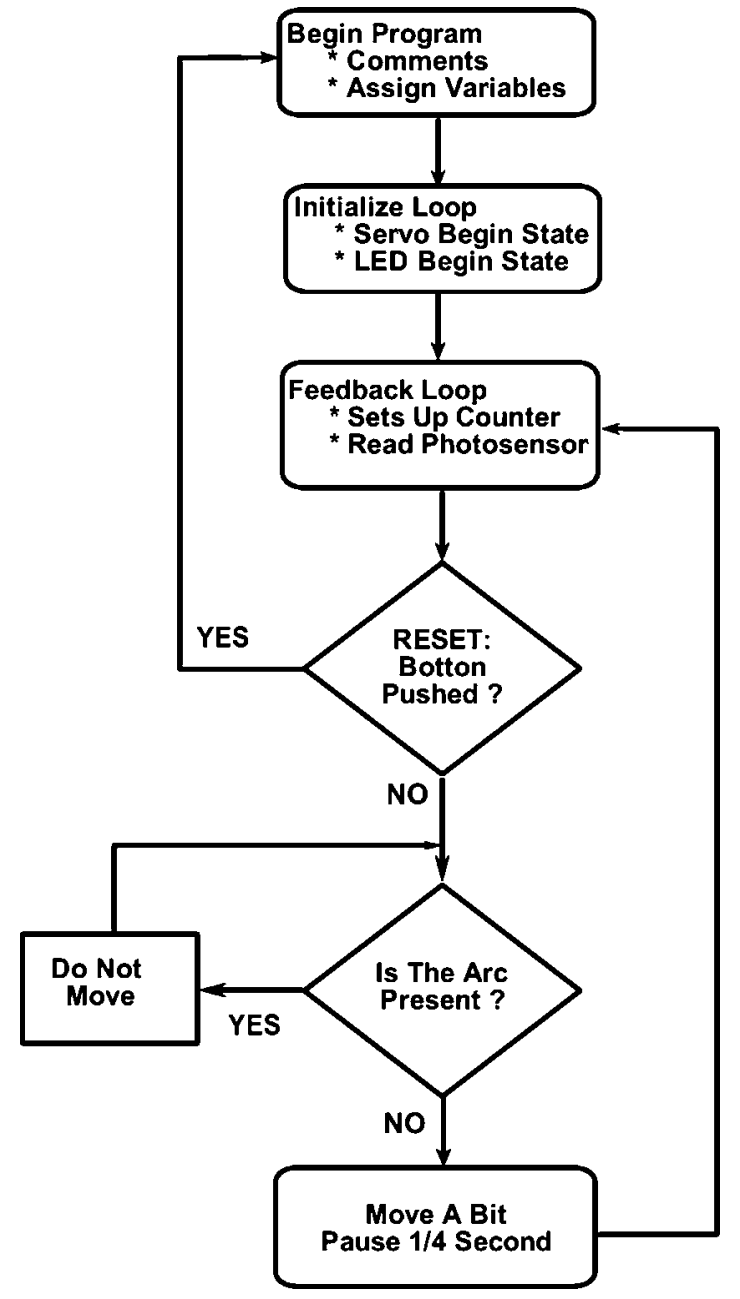

FIG. 5. The flow chart of the program for the integrated circuit of BASIC stamp for constant electrode feeding to maintain the arc in the ADS process.

program is shown in Fig. 5. During initialization of the program, the green LED is switched on, setting the initial $X, Y$, and $Z$ position specified by the user. The feedback loop can be activated when the START button is pressed on the circuit board. The feedback loop moves the $Z$-translational lever arm down through very precise movement of the servo. The feedback loop also is preceded by a check of the current signal from the photosensor. The servo continues downward until it gets a feedback from the photosensor. When the distance between the two electrodes is approximately $1 \mathrm{~mm}$, arc discharge starts and simultaneously the feedback loop gets the signal from the photosensor. The program is optimized to account for the inconsistency of the servo and the intrinsic instabilities created by the arc. The loop constantly checks the feedback reading from the photosensor. When the arc is diminished, the value of the photosensor signal increases, and the feedback loop activates the servo to drive the $Z$-translational lever towards the cathode, thereby maintaining the electrode gap constant.

\section{Testing of the automation: Synthesis of carbon nanostructures}

The synthesis of various carbon nanostructures by arc discharge has been carried out in aqueous solution. The syn- 
thesis of CNTs decorated with nanoparticles, such as palladium, nickel, silica, ceria, etc., was carried out in the precursor solutions. A solution of $\sim 2 \mathrm{mM}$ concentration was prepared by dissolving the appropriate precursor in deionized (DI) water. A detailed method of preparation of precursor solution can be found elsewhere. ${ }^{13}$ Two graphite electrodes with a diameter of $6.15 \mathrm{~mm}$, acting as a cathode and an anode, were immersed in the DI water or precursor solution inside the cell. The anode and the cathode were obtained from Alfa Aesar with $99.9995 \%$ purity. A direct current power supply (model: Dual Mig 131/2 by Chicago Electric, made in Italy), was connected to the graphite electrodes. The electrodes were brought in contact to strike an arc and the electrodes were separated immediately to a distance of about $1 \mathrm{~mm}$ to sustain the arc inside the solution. The synthesis was carried out at an open circuit potential of $28 \mathrm{~V}$ with an optimized direct current of $75 \mathrm{~A}$. The CNTs decorated with nanoparticles were collected from the solution for characterization.

To study the consumption of the electrode during the arc discharge in the solution, the weight and the length of the electrodes were monitored throughout the experiment during the synthesis of CNTs decorated with palladium nanoparticles. The initial weights of the two electrodes were recorded after taking them inside the furnace at $150{ }^{\circ} \mathrm{C}$ for $1 \mathrm{~h}$. The weight differences were measured every 2 min after drying off the electrode in the furnace for $30 \mathrm{~min}$ at $150{ }^{\circ} \mathrm{C}$. The evaporation rate of the solution has also been followed by measuring the volume of the solution after cooling down to room temperature.

\section{Characterizations of carbon nanostructures}

High-resolution transmission electron microscopy (HRTEM) and scanning transmission electron microscopy (STEM) using a FEI Tecnai F30 at $300 \mathrm{kV}$ were carried out to characterize the carbon nanostructures. For elemental analysis an energy dispersive spectroscopy (EDS) system attached to the TEM was used. The CNTs decorated with ceria nanoparticles were characterized using a JEOL T-300 SEM at an acceleration voltage of $5 \mathrm{kV}$.

\section{RESULT AND DISCUSSIONS}

CNTs and other carbonaceous materials including dislodged graphene sheets, carbon onions, amorphous carbon, and carbon rods have been found in arc discharge in a solution method. Such carbonaceous materials form inside the plasma region of the arc at various temperature zones. ${ }^{6}$ Figure 6 is representing different carbon nanostructures which formed during the arc discharge in deionized water. A HRTEM image of a CNT is shown in Fig. 6(a) synthesized during arc discharge in water. The inner diameter of all CNTs is typically $3 \mathrm{~nm}$. The minimum outer diameter is $5 \mathrm{~nm}$. The diameter of the CNTs is found to be in the range of $5-15 \mathrm{~nm}$. The distance between the two concentric walls is approximately $0.36 \mathrm{~nm}$ which is similar to the interlayer spacing ${ }^{16}$ in graphite of $0.37 \mathrm{~nm}$. Figure 6(b) shows a HRTEM image of a carbon nanorod. Such a carbon nanorod is very rare for an arc-discharge method in solution. An ample of amorphous
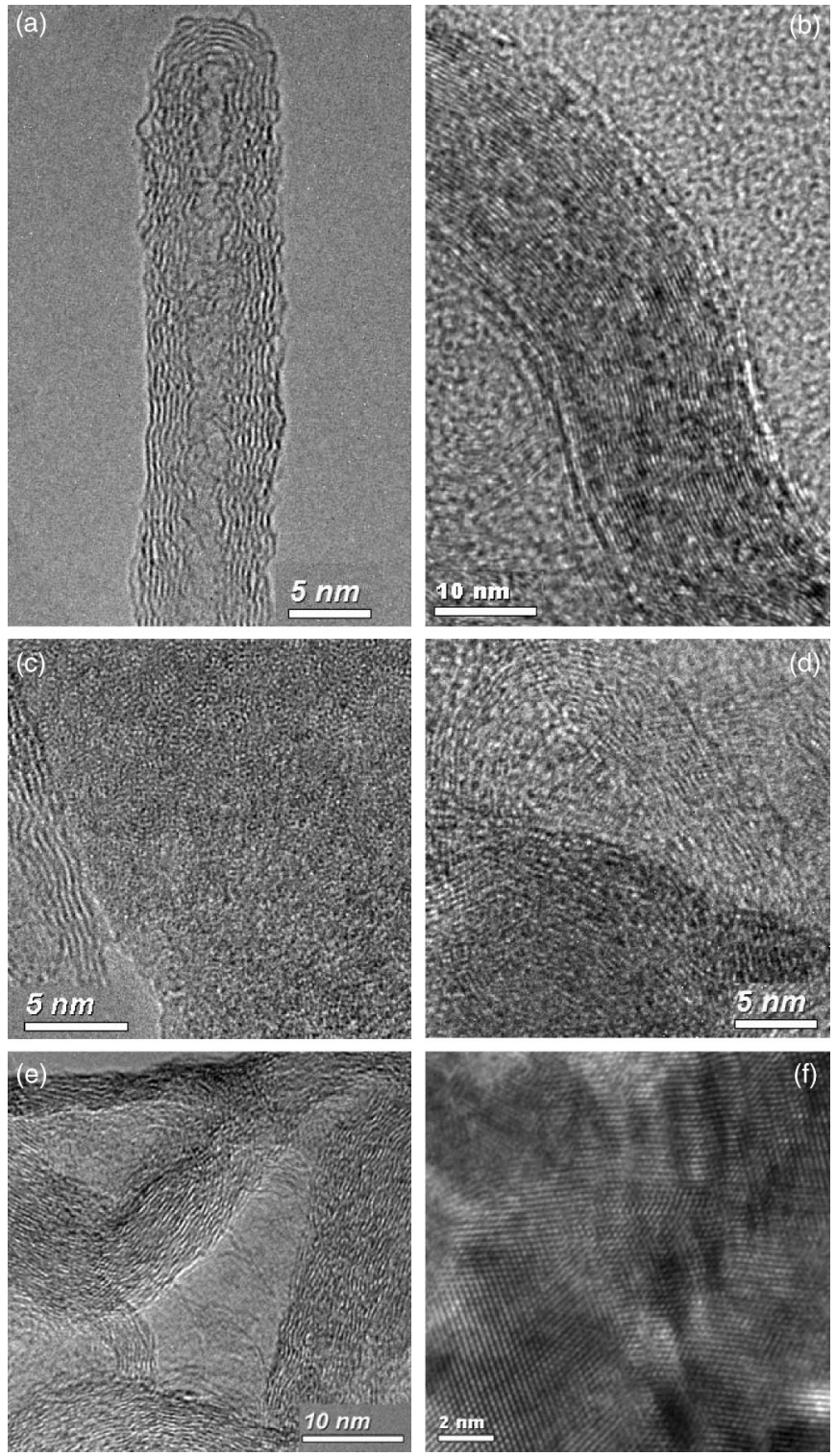

FIG. 6. Various nanostructures synthesized using ADS method; (a) carbon nanotube (CNT), (b) carbon nanorod, (c) amorphous carbon, (d) carbon onions, (e) nanoporous carbons, and (f) dislodged graphene sheets.

carbon is found on the holy-carbon TEM grids. Figure 6(c) is showing a micrograph of the amorphous carbon along with CNTs. Figure 6(d) is showing carbon onions. Such carbon onions are also found during the arc discharge in water by others. ${ }^{4,6}$ Nanoporous carbon was also found in this study and is shown in Fig. 6(e). A few dislodged graphene sheets were found during TEM analysis. One such dislodged graphene sheet is shown in Fig. 6(f).

This method has been successfully utilized to synthesize a number of metallic and oxide nanoparticles decorating CNTs. Figure 7(a) shows a SEM micrograph of clusters of ceria nanoparticles decorating CNTs. Figure 7(b) shows EDS spectrum of CNTs decorated with ceria nanoparticles taken during STEM analysis. CNTs decorated with silica nanoparticles are successfully synthesized using a $\mathrm{Si}$ precursor in the cell. The CNTs have been investigated with a scanning transmission electron microscopy (STEM) using a high-angle annular dark field detector for $z$-contrast imaging. A STEM 

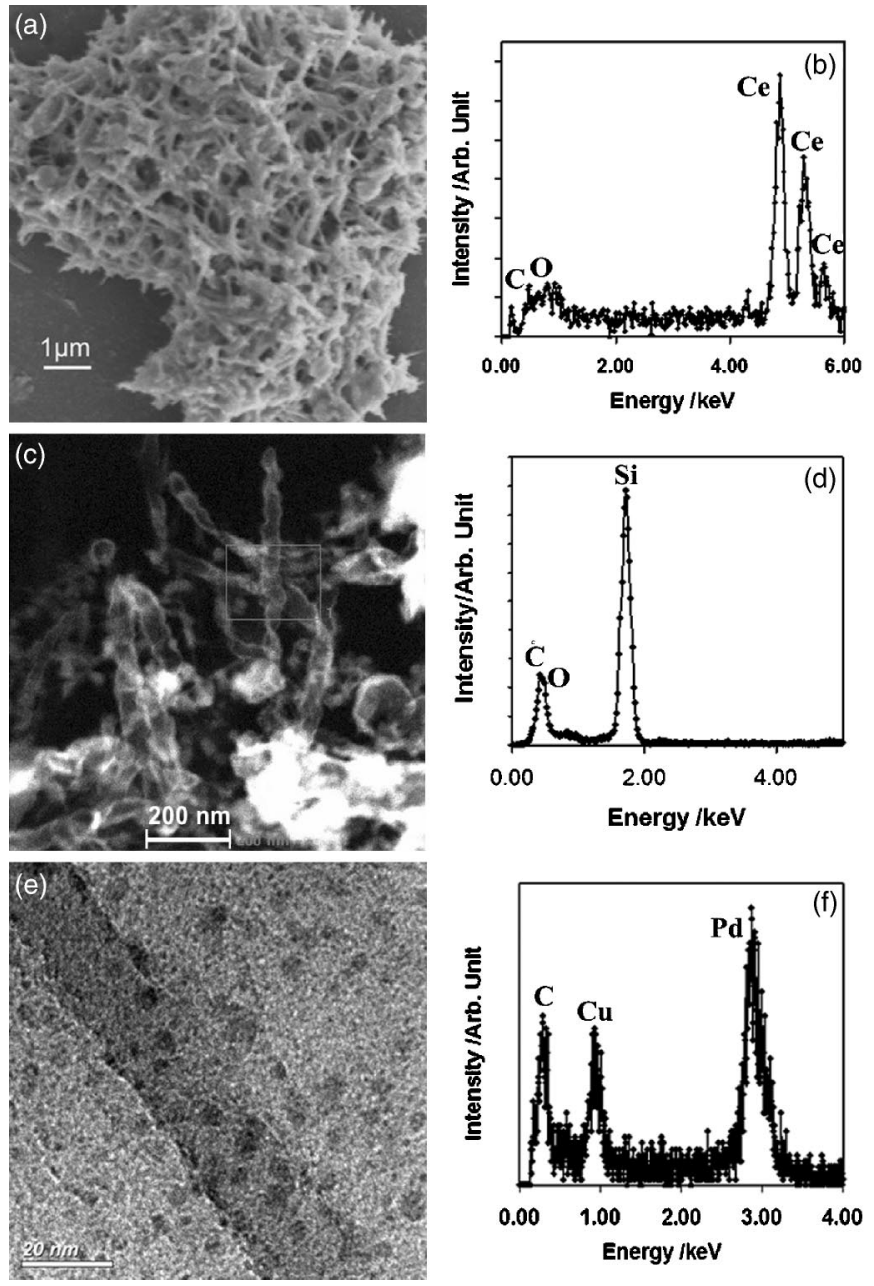

FIG. 7. (a) SEM micrograph of carbon nanotubes (CNTs) decorated with Ceria nanoparticles, (b) EDS spectrum of CNTs decorated with ceria (c) STEM micrograph of CNTs decorated with silica nanoparticles and (d) corresponding EDS; (e) HRTEM micrograph of CNTs decorated palladium nanoparticles; black dark spots are 3-4 nm palladium nanoparticles. (f) EDS spectrum of CNTs decorated with Pd-nanoparticles; the presence of $\mathrm{Cu}$ peak is due to $\mathrm{Cu}$ grid used during TEM investigation.

image and its corresponding EDS spectrum of CNTs decorated with silica nanoparticles are shown in Figs. 7(c) and 7 (d), respectively. The EDS spectrum was collected from the rectangular area shown inside the Fig. 7(c). A TEM brightfield image of a CNT decorated with palladium nanoparticles is shown in Fig. 7(e). The diameter of the CNT is about 15 $\mathrm{nm}$. The spherical dark regions in Fig. 7(e) correspond to the palladium nanoparticles with about $3 \mathrm{~nm}$ in diameter. Figure $7(\mathrm{f})$ is an EDS spectrum of palladium silica nanoparticles decorated CNTs collected during TEM investigation. The presence of a $\mathrm{Cu}$ peak in EDS spectrum is due to the use of copper grid in the TEM study.

For the synthesis of CNTs decorated with palladium nanoparticles, erosion behaviors of graphite electrodes and their consumption rates were determined by monitoring the change of the weights and lengths of the electrodes with time. Table I shows the weight change of each individual electrode and that of both together as a function of time. The weight change relationship in the present system can be mathematically expressed with the following equation:

$$
\Delta W=k \times t,
$$

where $t$ is time in minutes and $\Delta W$ is the weight change in $\mathrm{g} \mathrm{cm}^{-2}$ during arc discharge in solution, and $k$ is a normalized kinetic parameter in $\mathrm{g} \mathrm{cm}^{-2} \mathrm{~min}^{-1}$. The experimental values of $k$ in Eq. (1) for the cathode and the anode are 0.52 and $-2.73 \mathrm{~g} \mathrm{~cm}^{-2} \mathrm{~min}^{-1}$, respectively. The $k$ value of combine anode and cathode electrodes is $-2.17 \mathrm{~g} \mathrm{~cm}^{-2} \mathrm{~min}^{-1}$. The cathode gains weight with time whereas the anode loses weight during the arc discharge. The overall weight of the electrodes decreases with time. The excessive heat produced in the solution during arcing leads to partial evaporation of the solution. The evaporation rate of the water during arc discharge in solution in the present system was found to be $3.2 \mathrm{~cm}^{3} \mathrm{~min}^{-1}$. The temperature at the center of the arc is expected to be greater than $3500{ }^{\circ} \mathrm{C}$. Hence, the plasma region produced by the arc adjacent to the electrodes is enveloped by a solution-vapor interface. There is a substantial thermal gradient across the plasma region. The loss of weight of the electrodes is due to the formation of carbon dioxide, carbon monoxide, CNTs, and other carbonaceous materials as shown in Fig. 4. Such carbonaceous materials were possibly formed inside the plasma region in different temperature zones. ${ }^{6}$ Recently we have discussed ${ }^{14}$ changes of the morphologies during the experiments. The morphology ${ }^{14}$ of the anode surface is significantly altered during the arc discharge whereas that of the cathode surface has found to be uneven due to the deposition of the carbonaceous materials.

TABLE I. Erosion behaviors of electrodes with time.

\begin{tabular}{|c|c|c|c|c|}
\hline \multirow[t]{2}{*}{$\begin{array}{l}\text { Duration of } \\
\text { measurement } \\
\quad(\min )\end{array}$} & \multicolumn{2}{|c|}{$\begin{array}{c}\text { Difference in weight from initial } \\
\text { weight }\end{array}$} & \multirow[t]{2}{*}{$\begin{array}{c}\text { Cumulative } \\
\text { weight } \\
\text { difference }(\mathrm{g})\end{array}$} & \multirow[t]{2}{*}{$\begin{array}{c}\text { Difference in } \\
\text { volume [from } \\
\text { initial volume } \\
50 \mathrm{ml} \text { ( } \mathrm{ml})\end{array}$} \\
\hline & $\begin{array}{c}\text { Anode }(\mathrm{g}) \\
\text { [Initial weight: } \\
2.494 \mathrm{~g} \text { ] }\end{array}$ & $\begin{array}{c}\text { Cathode }(\mathrm{g}) \\
\text { [Initial weight: } \\
2.421 \mathrm{~g} \text { ] }\end{array}$ & & \\
\hline 0 & 0 & 0 & 0 & 0 \\
\hline 2 & -0.247 & 0.037 & -0.21 & -4 \\
\hline 4 & -0.678 & 0.128 & -0.55 & -7 \\
\hline 6 & -1.101 & 0.202 & -0.899 & -16 \\
\hline 8 & -1.639 & 0.319 & -1.32 & -27 \\
\hline 9 & -1.882 & 0.367 & -1.515 & -33 \\
\hline
\end{tabular}




\section{ACKNOWLEDGMENTS}

The authors would like to thank NSF-REU (NSF EEC: 0139614), NASA-Glenn for financial support, and the Materials Characterization Facility (MCF) of Advanced Materials Processing and Analysis Center (AMPAC) at the University of Central Florida (UCF) for equipment supports.

${ }^{1}$ W. A. de Heer, MRS Bull. 29, 281 (2004).

${ }^{2}$ J. Liu, S. Fan, and H. Dai, MRS Bull. 29, 244 (2004).

${ }^{3}$ M. Ishigami, J. Cumings, A. Zettl, and S. Chen, Chem. Phys. Lett. 319, 457 (2000)

${ }^{4}$ N. Sano, H. Wang, M. Chhowalla, I. Alexandrou, and G. A. J. Amaratunga, Nature (London) 414, 506 (2001).

${ }^{5}$ Y. L. Hsin, K. C. Hwang, F. Chen, and J. Kai, Adv. Mater. (Weinheim, Ger.) 13, 830 (2001).

${ }^{6}$ N. Sano, H. Wang, I. Alexandrou, M. Chhowalla, K. B. K. Teo, G. A. Amaratunga, and K. Iimura, J. Appl. Phys. 92, 2783 (2002).
${ }^{7}$ X. Li, H. Zhu, B. Jiang, J. Ding, X. Cailu, and D. Wu, Carbon 41, 1664 (2003).

${ }^{8}$ L. P. Biró, Z. E. Horváth, L. Szalmás, K. Kertész, F. Wéber, G. Juhász, G. Radnóczi, and J. Gyulai, Chem. Phys. Lett. 372, 399 (2003).

${ }^{9}$ N. Sano, H. Wang, M. Chhowalla, I. Alexandrou, G. A. J. Amaratunga, M. Naito, and T. Kanki, Chem. Phys. Lett. 368, 331 (2003).

${ }^{10}$ M. V. Antisari, R. Marazzi, and R. Krsmanovic, Carbon 41, 2393 (2003).

${ }^{11}$ H. Lange, M. Sioda, A. Huczko, Y. Q. Zhu, H. W. Kroto, and D. R. M. Walton, Carbon 41, 1617 (2003).

${ }^{12}$ J. Qiua, Y. Lia, Y. Wang, Z. Zhao, Y. Zhou, and Y. Wang, Fuel 83, 615 (2004).

${ }^{13}$ D. Bera, S. C. Kuiry, M. McCutchen, A. Kruize, H. Heinrich, M. Meyyappan, and S. Seal, Chem. Phys. Lett. 386, 364 (2004).

${ }^{14}$ D. Bera, S. C. Kuiry, M. McCutchen, S. Seal, H. Heinrich, and G. D. Slane, J. Appl. Phys. 96, 5152 (2004).

${ }^{15}$ H. Lange, P. Baranowski, A. Huczko, and P. Byszewski, Rev. Sci. Instrum. 68, 3723 (1997).

${ }^{16}$ R. S. Franklin, Proc. R. Soc. London, Ser. A 209, 196 (1951). 